\title{
Sex Steroids and Bone Mass
}

\author{
A Study of Changes About the Time of Menopause
}

Charles Slemenda, ${ }^{*}$ Siu L. Hui, ${ }^{*}$ Christopher Longcope, ${ }^{\star}$ and C. Conrad Johnston*

${ }^{*}$ Department of Medicine, Regenstrief Institute, Indiana University School of Medicine, Indianapolis, Indiana 46202; ${ }^{\ddagger}$ The

Departments of Obstetrics and Gynecology and Medicine, University of Massachusetts Medical School, Worcester, Massachusetts 01605

\begin{abstract}
To examine the relationships between bone loss and sex steroids, 84 peri- and postmenopausal women were studied at 4-mo intervals for 3 yr. At each visit, measurements were made of bone mass at the midshaft and distal radius, of steroids, of gonadotropins, and of bone gla protein (BGP). Bone loss was $\sim 1 \%$ per yr among late perimenopausal and postmenopausal groups, whereas the early perimenopausal group lost no bone. Mean serum estrogen and BGP concentrations predicted rates of bone loss. BGP was negatively correlated with the rate of bone loss $(r=-0.45)$ and with mean estrogen concentrations $(r$ $=-0.40)$. Multivariate regressions showed estrogen concentrations to be strong independent predictors of the slope of bone mass over time. When BGP concentrations were added to the models, the significance of estrogen was reduced, suggesting that a portion of the estrogen effect was mediated through effects on rates of bone remodelling.
\end{abstract}

\section{Introduction}

It is generally recognized that estrogen deficiency plays a role in the genesis of postmenopausal bone loss and the subsequent development of osteoporosis and its attendant fractures. There is controversy, however, regarding the importance of the natural menopause and the contribution of residual endogenous estrogen concentrations to rates of bone loss (1).

Oophorectomy is known to induce a phase of relatively rapid bone loss $(2,3)$ that is ameliorated with exogenous estrogen therapy $(4,5)$. Estrogen therapy has also been shown to reduce the rate of bone loss after natural menopause (6), as well as to reduce the incidence of vertebral deformities $(5,7)$. Some case-control studies have suggested that serum estrogens may be lower in patients with crush fractures (8), whereas others have found no such effect (9-11). Despite these results, disagreement still exists regarding the importance of natural menopause and its effects on the rate of bone loss from various sites. While it has been suggested that trabecular bone may be especially sensitive to the declining estrogen concentrations

An abstract was presented at the Society for Epidemiologic Research Meeting, University of Massachusetts, Amherst, MA. June 1986.

Send all reprint requests to Dr. C. Slemenda, Regenstrief Institute for Health Care, 5th Floor, 1001 West Tenth St., Indianapolis, IN 46202.

Received for publication 10 June 1986 and in revised form 20 April 1987.

J. Clin. Invest.

(c) The American Society for Clinical Investigation, Inc.

$0021-9738 / 87 / 11 / 1261 / 09 \$ 2.00$

Volume 80, November 1987, 1261-1269 that accompany menopause (12), it has also been argued that the decline in bone mass over time is little altered by menopause, with vertebral bone loss beginning at about age $40 \mathrm{yr}$ and continuing at an approximately constant rate thereafter $(13,14)$, although these same authors did find an accelerated appendicular rate of loss in the 51-65-yr age group. This phenomenon of bone loss around the time of menopause appears to affect the entire skeleton, and exogenous estrogen prophylaxis appears to be effective at all sites (15).

Published longitudinal studies of changes in bone mass associated with changes in endogenous estrogens are few. The importance of change in estrogen concentrations through menopause is unclear, although there is some suggestion that those who lose bone more rapidly have lower concentrations of estrone (E1) ${ }^{1}$ and estradiol (E2) (16). This study examined changes in bone mass, but made only a single measurement of hormones.

Thus, whether endogenous estrogens determine rates of bone loss through the period surrounding the cessation of menses, and whether the relatively low concentrations of estrogens, which prevail after menopause, continue to be important, remain unanswered questions. Furthermore, a proposed mechanism of the estrogen effect on bone, e.g., increased remodelling when estrogen concentrations decline (17-20), has also not been studied longitudinally.

Finally, the importance of other potential influences, such as smoking, obesity, and dietary factors have rarely been studied in conjunction with a longitudinal examination of bone mass and hormones through the menopause. The study described below examined bone, hormone, and other factors in a group of women prospectively around the time of menopause.

\section{Methods}

84 women aged 42-58 yr at entry were studied at 4-mo intervals for $\sim 3$ yr. At each visit, the following measurements were made: $(a)$ single-photon absorptiometry at two sites on the radius using a absorptiometer (Norland Cameron; Norland Instruments/INO-TECH, Inc., Fort Atkinson, WI) and (b) serum concentration of E1, E2, testosterone ( $\mathrm{T}$ ), androstenedione (A), follicle-stimulating hormone (FSH), and leutinizing hormone (LH). 3-d diet diaries were completed at baseline, as were measurements of hormone production and clearance rates and of peripheral aromatization. Subjects were interviewed to ascertain medical and menstrual history, use of medications, alcohol and tobacco, and demographic information.

Exclusion criteria were $(a)$ the use of exogenous estrogens, corticosteroids, or other medications known to affect bone; $(b)$ hysterectomy

1. Abbreviations used in this paper: A, androstenedione; BGP, bone gla protein; BMI, body-mass index; [ $\rho$ ], conversion rate; E1, estrone; E2, estradiol; FSH, follicle-stimulating hormone; $\mathrm{LH}$, leutinizing hormone; $\mathrm{MCR}$, metabolic clearance rate; $\mathrm{P}_{\mathrm{B}}$, production rate(s); $\mathrm{T}$, testosterone. 
and/or oophorectomy; (c) diabetes mellitus; $(d)$ life-threatening illnesses, such as cancer or severe cardiovascular disease; and $(e)$ disorders of the intestinal tract known to affect absorption.

Menopausal status was determined by interview and by measurements of gonadotropins. At each visit each volunteer answered questions regarding recent menstrual history. After $1 \mathrm{yr}$ of follow-up, subjects were defined as postmenopausal if there was complete absence of menstrual cycles since the beginning of the study $(n=45)$. The early postmenopausal $(n=14$ of 45$)$ were at entry to the study $<1$ yr since the cessation of menses, and the late postmenopausal ( $n=31$ of 45$)$ were between 1 and $5 \mathrm{yr}$ postmenopausal. The remaining 39 subjects cycled irregularly during this $1 \mathrm{st}$ yr and were considered perimenopausal. This group was divided into the late perimenopausal $(n=20)$, who had concentrations of FSH $>40 \mathrm{mIU} / \mathrm{ml}$ on at least two occasions during the 1st yr, and the early perimenopausal $(n=19)$, who were cycling irregularly but did not show consistently elevated concentrations of FSH. Thus, the menopausal status of subjects in this study was defined based on menstrual history and gonadotropin concentrations during year one of this 3-yr study. 21 subjects from the perimenopausal group became postmenopausal during the last $2 \mathrm{yr}$ of the study.

Single-photon absorptiometry was performed on the midshaft radius at a point one-third of the distance from the radial styloid to the olecranon and on the distal radius at $10 \%$ of this same distance. The absorptiometry was done using an iodine source with one-eighth-in. beam collimation (21). The midshaft site is $\sim 98 \%$ cortical bone, whereas the distal site is $~ 70 \%$ cortical and $30 \%$ trabecular bone (22). In vivo precision, assuming linear changes in bone mass, based on 893 radius measurements over $3 \mathrm{yr}$ in 84 women, was $3.1 \%$ for the distal and $2.4 \%$ for the midshaft measurements.

$\mathrm{E} 1, \mathrm{E} 2, \mathrm{~T}$, and A were measured by radioimmunoassay $(23,24)$. Briefly, 20-ml blood samples were drawn, centrifuged, and analyses done on plasma. The analyses involved solvent extraction and celite chromatography for steroid purification, followed by immunoassay using specific antibodies and dextran-coated charcoal to separate free and bound steroid. Gonadotropins (FSH and LH) were measured using standard kits obtained from Serono (Serono Laboratories Co., Braintree, MA). Metabolic clearance (MCR) and production $\left(\mathrm{P}_{\mathrm{B}}\right)$ rates and conversions $[\rho]^{\text {precursor,product }}$ or $[\rho]^{\text {androgen,estrogen }}$ were measured as previously described $(25,26)$. Briefly, while fasting and supine, subjects received a priming dose of $\left[{ }^{3} \mathrm{H}\right]$ androgen and $\left[{ }^{14} \mathrm{C}\right]$ estrogen, followed by a constant infusion of the radiolabeled steroids for $3.5 \mathrm{~h}$. During the last hour of the infusion, blood was drawn three times and the plasma was stored frozen. All urine was collected for $96 \mathrm{~h}$ and stored frozen.

Each subject was infused with $\left[{ }^{3} \mathrm{H}\right] \mathrm{A} /\left[{ }^{14} \mathrm{C}\right] \mathrm{E} 1$ and $\left[{ }^{3} \mathrm{H}\right] \mathrm{T} /\left[{ }^{14} \mathrm{C}\right] \mathrm{E} 2$. The infusions were 1 wk apart, and before each infusion a blood sample was obtained and the plasma concentrations of A, T, E1 and E2 were determined. The mean of these two values was used to determine the $P_{B}$ of each steroid. For women who were still having menstrual cycles, the infusions were done in the early- to mid-follicular phase.

Analysis of the plasma samples involved solvent extraction and multiple chromatographic and derivatization steps to achieve radiochemical purity (25). The radioactivity in each steroid was measured in a liquid scintillation spectrometer and corrected for losses through the procedure as described (26). The MCRs and $P_{B}$ were calculated as follows (27): $M C R=r / \bar{x}$ where $r$ designates rate of infusion (disintegrations per minute per day) and $\bar{x}$, mean concentration of infused steroids (disintegrations per minute per liter); $P_{B}=M C R \times i$ where $i$ measures concentration of steroid as determined by radioimmunoassays.

Urines were analyzed as described (28). Briefly, unconjugated steroids were extracted using cyclohexane-ethylacetate $(1: 2 \mathrm{vol} / \mathrm{vol})$ and the urine was incubated with $\beta$-glucuronidase. The hydrolyzed steroids were extracted with cyclohexane-ethylacetate $(1: 2 \mathrm{vol} / \mathrm{vol})$ and purified by alkaline partition and multiple chromatographic and derivatization steps. The radioactivity as E1, E2, and estriol was measured using a liquid scintillation spectrometer. [ $\rho]_{\text {blood, metabolite }}^{\text {andogen }}$ (the percent of androgen infused that is converted to estrogen in the body) is calcu- lated $\left[\left(\left[{ }^{3} \mathrm{H}\right] \text { estrogen } /\left[{ }^{14} \mathrm{C}\right] \text { estrogen }\right)_{\text {urine }} /\left(\left[{ }^{3} \mathrm{H}\right]\right.\right.$ androgen $/\left[{ }^{14} \mathrm{C}\right]-$ estrogen $\left.)_{\text {infused }}\right] \times 100(28)$.

Bone gla protein (BGP) was measured using a method previously described (29).

Dietary calcium, protein, phosphorus, and caffeine (from chocolate, coffee, tea, and cola soft drinks) were estimated from 3-d diet diaries, coded by registered dietitians and analyzed using a modification of the U.S. Department of Agriculture Handbook 456. Interviews were used to assess smoking, medical and surgical history, alcohol intake, and drug use. Body-mass index (BMI) was calculated as weight (kilogram) divided by height squared (meters squared).

Statistical methods. Rates of bone loss for each individual, and the inter- and intrasubject variances were calculated according to the method of Hui (30). Group means were compared using $t$ tests for independent samples with separate variances. Multiple group comparisons were done by analysis of variance with Tukey's test for pairwise contrasts. Pearson correlations and general linear models (weighted by the inverse of the sum of the inter- and intraperson variances) were performed using a statistical analysis package (Statistical Analysis System User's Guide, 1985 Version 5; SAS Inst. Inc., Cary, NC).

\section{Results}

Table I displays the mean ages, BMIs, and months since last menses for each of the four groups. The early perimenopausal women were on average $2.6 \mathrm{yr}$ younger than late perimenopausal women $(P<0.05)$. The late perimenopausal and early postmenopausal groups did not differ significantly in age (0.3 yr).

Table II presents the rates of change in bone mass and the mean concentrations of the sex steroids and BGP over $3 \mathrm{yr}$. The early perimenopausal group was not losing bone at either the midshaft $(+0.0005 \mathrm{~g} / \mathrm{cm}$ per yr) or distal $(+0.0067 \mathrm{~g} / \mathrm{cm}$ per yr) radius, whereas each of the other three groups had rates of bone loss significantly different from zero, and not significantly different from one another; i.e., the late perimenopausal and both postmenopausal groups had not significantly different rates of bone loss. Likewise, the early perimenopausal group had a mean concentration of BGP at $2 \mathrm{ng} / \mathrm{ml}$ lower than the late perimenopausal group (Table II) that in turn differed by only $0.3 \mathrm{ng} / \mathrm{ml}$ from the early postmenopausal group and by $0.8 \mathrm{ng} / \mathrm{ml}$ from the late postmenopausal group. Similarly, with respect to the estrogens, the early perimenopausal differed significantly from the late perimenopausal by $42 \mathrm{pg} / \mathrm{ml}$ (E1) and $59 \mathrm{pg} / \mathrm{ml}(\mathrm{E} 2)$, whereas the late perimenopausal group had $\mathrm{E} 1$ concentrations only $6 \mathrm{pg} / \mathrm{ml}$ higher and E2 concentrations $16 \mathrm{pg} / \mathrm{ml}$ higher than the early postmenopausal group (both NS). There were no consistent patterns across groups with respect to the mean androgen concentrations, although the early perimenopausal group had slightly higher A concentrations.

Table I. Baseline Characteristics

\begin{tabular}{|c|c|c|c|c|c|}
\hline & $\begin{array}{l}\text { Early peri- } \\
\text { menopausal }\end{array}$ & $\begin{array}{l}\text { Late peri- } \\
\text { menopausal }\end{array}$ & $\begin{array}{l}\text { Early post- } \\
\text { menopausal }\end{array}$ & $\begin{array}{l}\text { Late post- } \\
\text { menopausal }\end{array}$ & $\begin{array}{l}P \\
(F \text { test })\end{array}$ \\
\hline & $n=19$ & $n=20$ & $n=14$ & $n=31$ & \\
\hline Age $(y r)$ & 48.2 & 50.8 & 51.1 & 53.0 & 0.001 \\
\hline $\mathrm{BMI}\left(\mathrm{kg} / \mathrm{m}^{2}\right)$ & 23.8 & 24.4 & 25.1 & 22.3 & 0.10 \\
\hline LMP $(m o)$ & 0.2 & 2.0 & 5.3 & 27.7 & 0.001 \\
\hline
\end{tabular}


Table II.

\begin{tabular}{|c|c|c|c|c|c|}
\hline & Early perimenopausal & Late perimenopausal & $\begin{array}{l}\text { Early } \\
\text { postmenopausal }\end{array}$ & Late postmenopausal & $P(F$ test $)$ \\
\hline & $n=19$ & $n=20$ & $n=14$ & $n=31$ & \\
\hline $\begin{array}{c}\text { Midshaft rate of } \\
(\mathrm{g} / \mathrm{cm} \text { per } y r)\end{array}$ & $+0.005 \pm 0.0070^{*}$ & $-0.0058 \pm 0.0101^{\ddagger}$ & $-0.0065 \pm 0.0178^{\ddagger}$ & $-1.0103 \pm 0.0121^{\ddagger}$ & 0.03 \\
\hline \multicolumn{6}{|c|}{ Distal rate of change } \\
\hline (g/cm per yr) & $+0.0067 \pm 0.0183^{*}$ & $-0.0095 \pm 0.0173^{\ddagger}$ & $-0.0159 \pm 0.0181^{\ddagger}$ & $-0.0110 \pm 0.0187^{\ddagger}$ & 0.002 \\
\hline BGP $(n g / m l)$ & $4.8 \pm 1.4^{\S}$ & $6.8 \pm 1.6$ & $7.0 \pm 2.1$ & $7.5 \pm 3.3$ & 0.001 \\
\hline $\mathrm{E} 1(\mathrm{pg} / \mathrm{ml})$ & $88.0 \pm 22.2^{\S}$ & $46.2 \pm 17.5$ & $40.2 \pm 7.8$ & $36.0 \pm 6.9$ & 0.001 \\
\hline $\mathrm{E} 2(\mathrm{pg} / \mathrm{ml})$ & $107.3 \pm 43.1^{8}$ & $48.2 \pm 26.8$ & $32.4 \pm 12.3$ & $24.7 \pm 7.3$ & 0.001 \\
\hline $\mathrm{T}(n g / m l)$ & $0.19 \pm 0.05$ & $0.19 \pm 0.06$ & $0.20 \pm 0.06$ & $0.18 \pm 0.06$ & NS \\
\hline $\mathrm{A}(n g / m l)$ & $0.65 \pm 0.38$ & $0.48 \pm 0.22$ & $0.48 \pm 0.17$ & $0.48 \pm 0.23$ & 0.09 \\
\hline
\end{tabular}

Note that pairwise contrasts were made by Tukey's test, which controls for multiple comparisons. Bonferroni's test yielded identical results. * Significantly different from the late postmenopausal; not significantly different from zero. ${ }^{\ddagger}$ Significantly different from zero; not significantly different from each other. ${ }^{\S}$ Significantly different from all other groups (except BGP when compared with late perimenopausal, $P=0.06$ ).

Table III summarizes the $P_{B}$, MCR, and aromatization rate for the four groups. Again, only the early perimenopausal group was significantly different from any other, having greater $P_{B}$ of $E 1$ and $E 2$ than the late perimenopausal and both postmenopausal groups. The late perimenopausal group did not differ in estrogen production from either of the postmenopausal groups.

MCR and aromatization rate were similar in all four groups (Table III).

Summarizing Tables I, II, and III, the early perimenopausal women were significantly different from the late perimenopausal and both groups of postmenopausal women with respect to rates of change in bone mass, $P_{B}$ and mean concentrations of the estrogens, and age. Of perhaps greater importance, the late perimenopausal women were not significantly different from the early postmenopausal group on any measured variable, and differed from the late postmenopausal only once (mean E2 concentration). Thus, the late perimenopausal and both postmenopausal groups are combined for some analyses. The purpose of this approach is to examine bone loss in a group with more homogeneous concentrations of E1 and E2, thereby reducing the possibility that outliers (i.e., those with very high estrogens and low bone loss) might have a disproportionate influence on the results of regression analyses. As shown in Table IV, the early perimenopausal group showed no loss of bone at either site, whereas the late peri-plus postmenopausal groups $(n=65)$ lost midshaft bone at $0.93 \%$ per yr and distal radius bone at $1.19 \%$ per yr. Similarly, the early perimenopausal group had significantly higher concentrations of E1 $(89.3$ vs. $39.4 \mathrm{pg} / \mathrm{ml}, P<0.001)$, and E2 (108.6 vs. 31.5 $\mathrm{pg} / \mathrm{ml}, P<0.001)$, and $\mathrm{A}(0.67$ vs. $0.48 \mathrm{ng} / \mathrm{ml}, P<0.05)$.

For the entire study group the rate of change at the midshaft $(-0.56 \mathrm{~g} / \mathrm{cm}$ per $\mathrm{yr},-0.66 \%$ per $\mathrm{yr})$ was correlated with the rate of change at the distal site $(-0.64 \mathrm{~g} / \mathrm{cm}$ per $\mathrm{yr},-0.71 \%$

Table III.

\begin{tabular}{|c|c|c|c|c|c|}
\hline & $\begin{array}{l}\text { Early } \\
\text { perimenopausal }\end{array}$ & $\begin{array}{l}\text { Late } \\
\text { perimenopausal }\end{array}$ & $\begin{array}{l}\text { Early } \\
\text { postmenopausal }\end{array}$ & $\begin{array}{l}\text { Late } \\
\text { postmenopausal }\end{array}$ & $P(F$ test $)$ \\
\hline & $n=19$ & $n=20$ & $n=14$ & $n=31$ & \\
\hline \multicolumn{6}{|c|}{ Production rates $(\mu g / d)$} \\
\hline E1 & $145 \pm 114^{*}$ & $85 \pm 65^{\ddagger}$ & $56 \pm 26^{\ddagger}$ & $44 \pm 21^{\ddagger}$ & 0.001 \\
\hline E2 & $161 \pm 140^{*}$ & $77 \pm 80^{\ddagger}$ & $27 \pm 16^{\ddagger}$ & $19 \pm 11$ & 0.001 \\
\hline $\mathbf{T}$ & $106 \pm 64$ & $94 \pm 54$ & $92 \pm 46$ & $79 \pm 41$ & NS \\
\hline $\mathbf{A}$ & $0.079 \pm 0.38$ & $0.85 \pm 0.63$ & $0.49 \pm 0.20$ & $0.61 \pm 0.32$ & NS \\
\hline \multicolumn{6}{|c|}{ Metabolic clearance $\left(\mathrm{ld} / \mathrm{m}^{2}\right)$} \\
\hline E1 & $1525 \pm 479$ & $1449 \pm 458$ & $1645 \pm 584$ & $1320 \pm 276$ & NS \\
\hline E2 & $1096 \pm 327$ & $1050 \pm 254$ & $1056 \pm 371$ & $961 \pm 287$ & NS \\
\hline $\mathbf{T}$ & $471 \pm 132$ & $478 \pm 197$ & $499 \pm 198$ & $432 \pm 114$ & NS \\
\hline A & $1758 \pm 410$ & $1781 \pm 419$ & $1779 \pm 349$ & $1645 \pm 452$ & NS \\
\hline \multicolumn{6}{|c|}{ Aromatization } \\
\hline$[\rho]^{\mathrm{T}, \mathrm{E} 2}$ & $0.0043 \pm 0.0019$ & $0.0043 \pm 0.0019$ & $1.1157 \pm 0.0038$ & $0.0046 \pm 0.0023$ & NS \\
\hline$[\rho]^{\mathrm{A}, \mathrm{E} 1}$ & $0.0210 \pm 0.0077$ & $0.0210 \pm 0.0066$ & $0.0260 \pm 0.0092$ & $0.0220 \pm 0.0075$ & NS \\
\hline
\end{tabular}

* Significantly different from all other groups. ${ }^{\ddagger}$ Not significantly different from each other. 


\begin{tabular}{|c|c|c|c|c|c|}
\hline & \multicolumn{2}{|c|}{ Early perimenopausal (mean \pm SD) } & \multicolumn{2}{|c|}{$\begin{array}{l}\text { Late peri- and postmenopausal } \\
\text { (mean } \pm S D)\end{array}$} & \multirow[t]{2}{*}{$P$} \\
\hline & $n=19$ & & $n=65$ & & \\
\hline Age $(y r)$ & 48.2 & 3.1 & 51.9 & 2.9 & 0.0001 \\
\hline BMI $\left(k g / m^{2}\right)$ & 23.8 & 3.8 & 23.5 & 4.1 & NS \\
\hline Months since last menses & 0.3 & 0.5 & 14.9 & 14.6 & 0.0001 \\
\hline Midshaft mass $(\mathrm{g} / \mathrm{cm})$ & 0.86 & 0.11 & 0.83 & 0.11 & NS \\
\hline Distal mass $(\mathrm{g} / \mathrm{cm})$ & 0.93 & 0.15 & 0.90 & 0.13 & NS \\
\hline Midshaft loss ( $\mathrm{g} / \mathrm{cm}$ per $\mathrm{yr}$ ) & +0.0015 & 0.0071 & -0.0077 & 0.0133 & 0.0002 \\
\hline Distal loss ( $\mathrm{g} / \mathrm{cm}$ per $y r)$ & +0.0082 & 0.0181 & -0.011 & 0.0192 & 0.005 \\
\hline $\mathrm{E} 1(\mathrm{pg} / \mathrm{ml})$ & 89.3 & 26.2 & 39.4 & 13.0 & 0.0001 \\
\hline $\mathrm{E} 2(p g / m l)$ & 108.6 & 48.1 & 31.5 & 18.2 & 0.0001 \\
\hline $\mathrm{T}(n g / m l)$ & 0.19 & 0.05 & 0.19 & 0.06 & NS \\
\hline $\mathrm{A}(n g / m l)$ & 0.67 & 0.37 & 0.48 & 0.21 & 0.05 \\
\hline $\mathrm{BGP}(n g / m l)$ & 5.1 & 1.6 & 8.0 & 3.0 & 0.0001 \\
\hline
\end{tabular}

per yr) at $r=+0.35, P=0.001$ (based on an average of 10.6 measurements per person). Thus, on a population basis, rates of bone loss were similar at both sites, and more rapid loss at one site was correlated with more rapid loss at the other. However, the strength of the correlation was not enough to allow the use of measurements at one site in an individual to predict the behavior of bone at a second site.

For the entire study population the correlations between rates of bone loss and mean steroid concentrations, $P_{B}$ measurements, and mean BGP concentrations are shown in Table $V$. These correlations are based on the means of measurements (an average of 6.5 measurements per subject) of BGP and an average of 9.0 measurements of the steroids per subject to minimize the effect of within-subject random variation and to reflect average hormone concentration during the period of bone loss. The estrogens, E1 and E2, were correlated at $r$ $=+0.90(P<0.001)$. Both the mean concentrations and the $P_{B}$ of the estrogens were correlated with rates of change in bone, more positive slopes (i.e., less bone loss) being seen in

Table V. Correlation Coefficients

\begin{tabular}{lll} 
& $\begin{array}{l}\text { Change in midshaft } \\
\text { mass (slope) }\end{array}$ & $\begin{array}{l}\text { Change in distal } \\
\text { mass (slope) }\end{array}$ \\
\hline Mean E1 & $+0.24^{*}$ & $+0.36^{\ddagger}$ \\
Mean E2 & $+0.26^{*}$ & $+0.33^{\S}$ \\
Mean T & +0.13 & $+0.23^{*}$ \\
Mean A & +0.16 & +0.09 \\
$\mathrm{P}_{\mathrm{B}}$ of E1 & $+0.27^{\S}$ & $+0.28^{\S}$ \\
$\mathrm{P}_{\mathrm{B}}$ of E2 & $+0.39^{\ddagger}$ & $+0.29^{\S}$ \\
$\mathrm{P}_{\mathrm{B}}$ of T & $+0.35^{\ddagger}$ & +0.18 \\
$\mathrm{P}_{\mathrm{B}}$ of A & +0.16 & +0.05 \\
Mean BGP & $-0.48^{\ddagger}$ & $-0.44^{\ddagger}$ \\
\hline
\end{tabular}

\footnotetext{
* $P<0.05$

$\$ P<0.001$

$\S P<0.01$
}

those subjects with greater mean concentrations and $P_{B}$ of estrogens. Figs. 1 and 2 display the individual slopes of midshaft and distal radius bone mass plotted against the individual mean E2 concentration (separate regression lines for the early perimenopausal, $n=19$, and the late peri- plus postmenopausal, $n=65$, groups are shown). The mean serum $\mathrm{T}$ concentration was correlated with rate of bone loss at the distal site, but not at the midshaft, whereas the $P_{B}$ of $T$ correlated with rate of midshaft radial bone loss, but not distal loss. For $A$

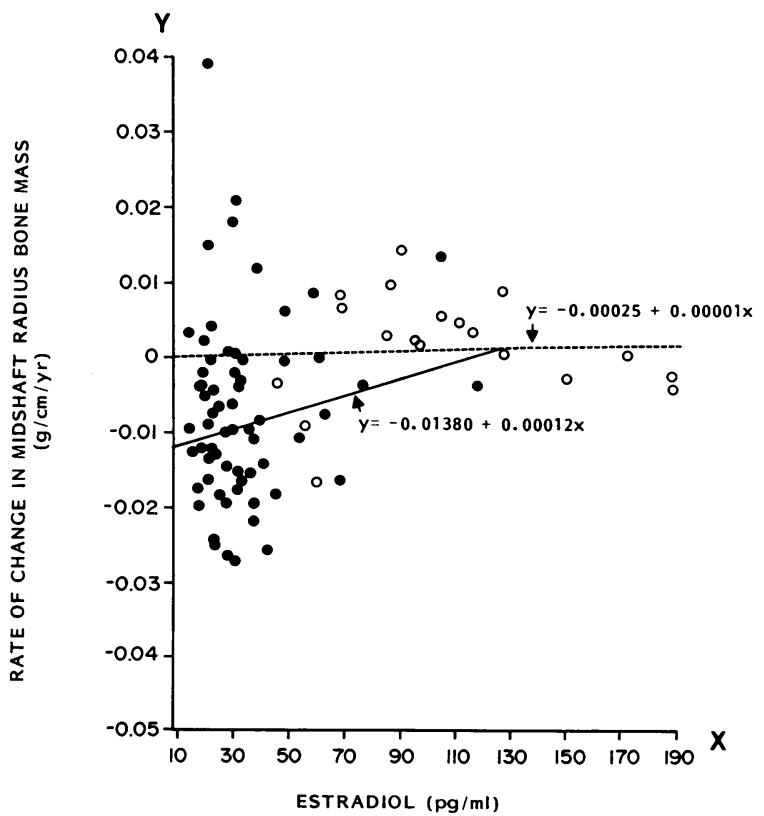

Figure 1. Plot of the individual rates of change in midshaft radius bone mass against the individual mean E2 concentrations. Solid line and circles indicate late perimenopausal plus both postmenopausal groups. Dotted line and open circles represent the early perimenopausal group. For the entire group $(n=84)$ the weighted regression is given by $y=0.01270+0.00011 x$. 


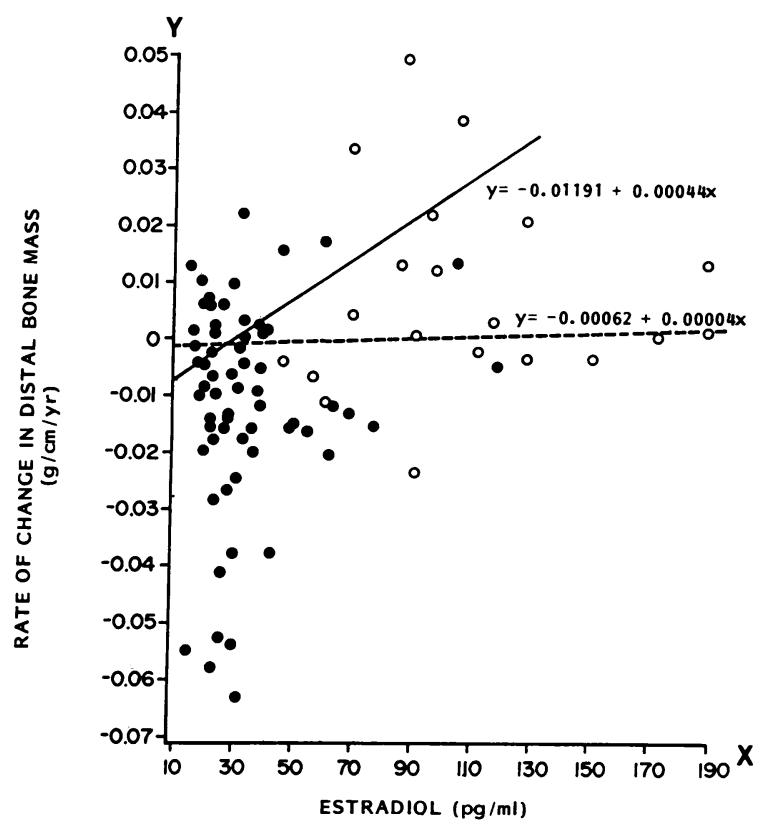

Figure 2. Plot of the individual rates of change in distal radius bone mass against the individual mean E2 concentrations. Solid line and circles indicate late perimenopausal plus both postmenopausal groups. Dotted line and open circles represent the early perimenopausal group. For the entire group $(n=84)$ the weighted regression is given by $y=0.01380+0.00013 x$.

neither concentrations nor $P_{B}$ were correlated with bone loss. However, the strongest correlates of bone loss were the plasma concentrations of BGP (Figs. 3 and 4). Both distal $(r=-0.44$,

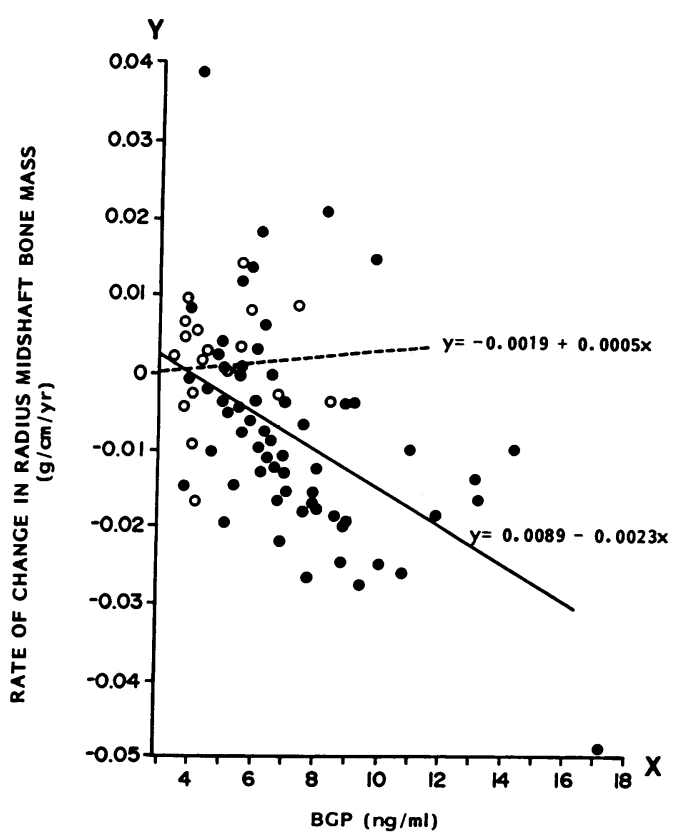

Figure 3. Plot of the individual rates of change in midshaft radius bone mass against the individual mean BGP concentrations. Solid line and circles indicate late perimenopausal plus early postmenopausal. Dotted line and open circles represent the early perimenopausal group. For the entire group $(n=84)$ the weighted regression is given by $y=0.0101-0.0024 x$.

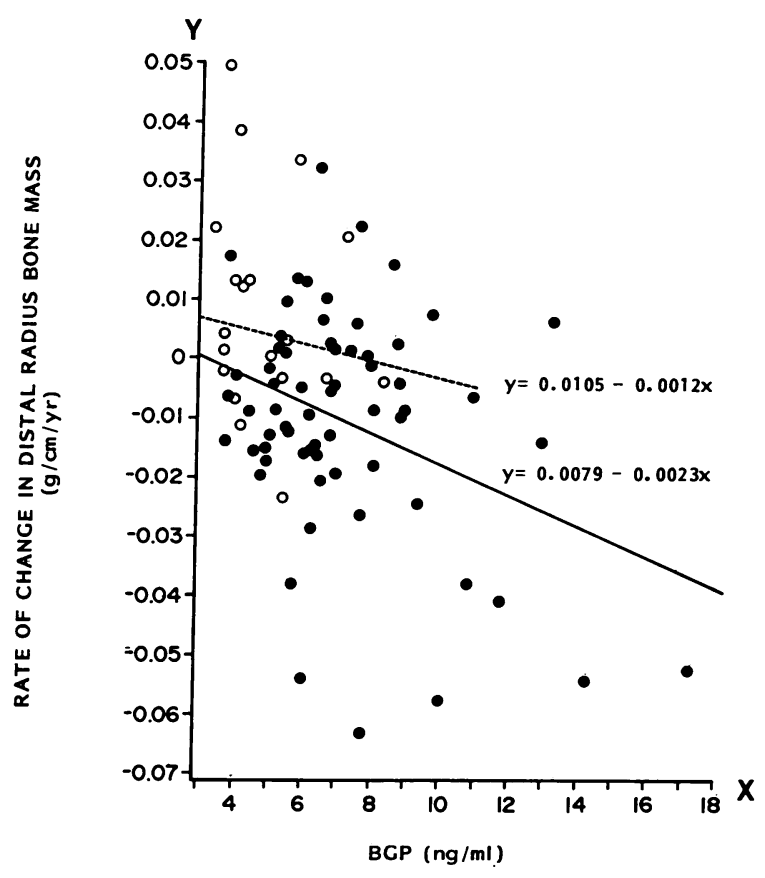

Figure 4. Plot of the individual rates of change in distal radius bone mass against the individual mean BGP concentrations. Solid line and circles indicate early perimenopausal plus both postmenopausal groups. Dotted line and open circles represent the early perimenopausal group. For the entire group $(n=84)$ the weighted regression is given by $y=0.0122-0.0027 x$.

$P=0.001)$ and midshaft $(r=-0.48, P=0.001)$ bone loss were correlated with BGP, indicating an association of greater losss with higher concentrations of BGP. Figs. 3 and 4 plot individual midshaft and distal bone mass slopes against individual mean BGP concentrations with regression equations as in Figs. 1 and 2.

Plasma BGP concentrations were also strongly correlated with E1 $(r=-0.42, P=0.0001)$ and E2 $(r=-0.39, P$ $=0.0002)$ concentrations.

The correlations between other potential influences and rates of bone loss were also examined by univariate analysis. These included pack-years of smoking (years smoking $\times$ average packs per day), BMI, alcohol intake, dietary calcium, protein, and caffeine intakes; none was significant in the complete group $(n=84)$, nor when the group was divided into peri- and postmenopausal. When these variables were included in multivariate models that included estrogen concentrations, none were significantly associated with changes in bone mass.

General linear models (multiple linear regressions) were constructed to predict the slopes of bone mass over time. Independent variables were selected for inclusion in the models if they were univariately associated with bone loss, if they were associated with bone loss in analysis of variance models, or if they were considered potentially important confounders. These were estrogen and androgen concentrations, dietary calcium and caffeine, pack-years smoking, and height. Age was tested as an independent variable in all models, but was never significant (probably due to the narrow range of ages) and is not included here. BGP was not included in the original models constructed since it was considered to be a reflection of the effects of other independent variables, such as estrogens 
(models that included BGP are considered below). Table VI displays the results of these initial analyses for both midshaft (top) and distal (bottom) radius measurements. Positive coefficients indicate an association with more positive slopes, i.e., with less bone loss. In these initial multiple linear regressions, mean estrogen concentrations (E1 or E2) over the study period were the strongest predictors $(P<0.001)$ of rates of midshaft and distal loss. Although all models shown use E2 as an independent variable, E1 concentrations were also examined, and yielded essentially identical results. $T$ concentrations also were positively associated with the slope of bone mass at the distal, but not the midshaft, radius. Other models were tested, including, as independent variables, the concentrations of progesterone, dehydroepiandrosterone and dehydroepiandrosterone sulfate, and the $P_{B}$ of estrogen and androgen. None was superior to those using mean estrogen concentrations.

Caffeine intake and smoking did not contribute to the explanation of the variance in bone loss at either site. Other variables (not shown), including BMI and ionized serum calcium, also did not contribute significantly. No potential confounding variables altered the estrogen-bone loss relationships.

Next, BGP was added to the original regression models. BGP was included as a marker of the rate of bone remodelling, a potential mode of action for estrogen effects on bone. E2 was negatively correlated with BGP $(r=-0.45, P<0.001)$. In the general linear models shown in Table VII, when BGP entered the model, the contribution of estrogen was reduced to marginal significance $(P=0.07)$, despite being highly significant $(P$ $<0.01)$ in simple linear regressions at both the midshaft and the distal sites. The inclusion of BGP did not, however, greatly affect the significance of $T$. Also, note that the beta coefficients of $\mathrm{E} 2$ are reduced by $60 \%$ when BGP is included, whereas the coefficients for $\mathrm{T}$ are unaffected.

Several approaches were used to test whether estrogen remains important when only those relatively estrogen-deficient women are considered. First, all information before meno-

Table VI.

Dependent variable: slope of midshaft mass over time (entire study group $[n=84])^{*}$

\begin{tabular}{|c|c|c|c|}
\hline & \multicolumn{2}{|c|}{ Independent variables $(U)$} & \multirow{2}{*}{$\begin{array}{l}\text { Percent variance } \\
\text { (by stepwise } \\
\text { regression) }\end{array}$} \\
\hline & $\hat{\beta}$ & $P$ & \\
\hline & & & $\%$ \\
\hline $\mathrm{E} 2(\mathrm{pg} / \mathrm{ml})$ & +0.000106 & 0.0001 & 14.6 \\
\hline
\end{tabular}

Dependent variable: slope of distal mass over time (entire study group $[n=84])^{\ddagger}$

\begin{tabular}{|c|c|c|c|}
\hline & \multicolumn{2}{|c|}{ Independent variables $(U)$} & \multirow{2}{*}{$\begin{array}{l}\text { Percent variance } \\
\text { (by stepwise } \\
\text { regression) }\end{array}$} \\
\hline & $\hat{\beta}$ & $P$ & \\
\hline & & & $\%$ \\
\hline $\mathrm{E} 2(p g / m l)$ & +0.000111 & 0.016 & 9.5 \\
\hline $\mathrm{T}(n g / m l)$ & +0.0639 & 0.05 & 4.1 \\
\hline Total variance & & & 13.6 \\
\hline
\end{tabular}

* Original model also included A, calcium, height, caffeine, and smoking (NS).

‡ Original model also included height, caffeine, smoking, and calcium (NS).
Table VII.

Dependent variable: slope of midshaft mass over time (entire study group $[n=84]$ ) (model includes BGP)*

\begin{tabular}{|c|c|c|c|}
\hline & \multicolumn{2}{|c|}{ Independent variables $(U)$} & \multirow{2}{*}{$\begin{array}{l}\text { Percent variance } \\
\text { (by stepwise } \\
\text { regression) }\end{array}$} \\
\hline & $\hat{\beta}$ & $P$ & \\
\hline & & & $\%$ \\
\hline $\mathrm{E} 2(p g / m l)$ & +0.000047 & 0.07 & 14.6 \\
\hline $\mathrm{BGP}(n g / m l)$ & -0.0021 & 0.0001 & 26.2 \\
\hline Total variance & & & 40.8 \\
\hline
\end{tabular}

Distal rate of change (entire study group $[n=84]$ ) (model includes BGP) ${ }^{\ddagger}$

\begin{tabular}{|c|c|c|c|}
\hline & \multicolumn{2}{|c|}{ Independent variables $(U)$} & \multirow{2}{*}{$\begin{array}{l}\text { Percent variance } \\
\text { (by stepwise } \\
\text { regression) }\end{array}$} \\
\hline & $\hat{\beta}$ & $P$ & \\
\hline & & & $\%$ \\
\hline $\mathrm{E} 2(p g / m l)$ & +0.000047 & 0.29 & 9.5 \\
\hline $\mathrm{T}(n g / m l)$ & +0.0642 & 0.03 & 4.1 \\
\hline $\mathrm{BGP}(n g / m l)$ & -0.00234 & 0.0001 & 15.1 \\
\hline Total variance & & & 28.7 \\
\hline
\end{tabular}

* Original model also included T, height, calcium, smoking, and caffeine (NS).

‡ Original model also included calcium, height, caffeine, and smoking (NS).

pause was deleted ( 222 bone mass measurements), leaving 66 subjects followed longitudinally with at least three postmenopausal visits. Among these $66, \mathrm{E} 1$ was significantly correlated with the change in distal radius bone mass $(r=+0.30, P$ $=0.016$ ), but not with the midshaft rate of change. A second approach to eliminate the influence of extreme estrogen values was to exclude all first year visits of the two perimenopausal groups; this yielded similar results to the first. Finally, because the late perimenopausal group was shown (Tables I, II, and III) to be similar to the postmenopausal groups, and significantly different in all important respects from the early perimenopausal group, the late perimenopausal and both postmenopausal groups were combined, yielding 65 women whose hormonal characteristics were similar. The mean concentration of E1 for this group was $39 \mathrm{pg} / \mathrm{ml} \mathrm{(} 36 \mathrm{pg} / \mathrm{ml}$ for the postmenopausal groups) and of E2, $32 \mathrm{pg} / \mathrm{ml}(25 \mathrm{pg} / \mathrm{ml}$ for the postmenopausal only). The association of estrogen with bone loss in this relatively estrogen-deficient group was somewhat weaker. Table VIII shows the results of these general linear models. At the midshaft radius, E2 (significant in simple linear regressions that excluded BGP, $P=0.04$ ) was reduced to nonsignificance $(P=0.44)$ when BGP was included in the model. At the distal site E2 was not significant, but $\mathrm{T}$ concentrations were positively associated with the change in distal bone mass. At both sites, greater concentrations of BGP were strongly associated with greater bone loss.

\section{Discussion}

Riis et al. (16) have shown that shortly after menopause those subjects losing bone most rapidly were those with the lowest concentrations of E1 and E2. However, the results of the pro- 
Table VIII.

Dependent variable: slope of midshaft mass over time (late perimenopausal plus postmenopausal $[n=65]]^{*}$

\begin{tabular}{|c|c|c|c|}
\hline & \multicolumn{2}{|c|}{ Independent variables $(U)$} & \multirow{2}{*}{$\begin{array}{l}\text { Percent variance } \\
\text { (by stepwise } \\
\text { regression) }\end{array}$} \\
\hline & $\hat{\boldsymbol{\beta}}$ & $P$ & \\
\hline & & & $\%$ \\
\hline $\mathrm{E} 2(\mathrm{pg} / \mathrm{ml})$ & +0.000046 & 0.44 & 4.5 \\
\hline \multirow[t]{2}{*}{$\mathrm{BGP}(n g / m l)$} & -0.00226 & 0.0001 & 33.1 \\
\hline & & & 37.6 \\
\hline
\end{tabular}

Dependent variable: slope of distal mass over time (late perimenopausal plus postmenopausal $[n=65])^{\ddagger}$

\begin{tabular}{|c|c|c|c|}
\hline & \multicolumn{2}{|c|}{ Independent variables $(U)$} & \multirow{2}{*}{$\begin{array}{l}\text { Percent variance } \\
\text { (by stepwise } \\
\text { regression) }\end{array}$} \\
\hline & $\hat{\boldsymbol{\beta}}$ & $P$ & \\
\hline & & & $\%$ \\
\hline $\mathrm{E} 2(\mathrm{pg} / \mathrm{ml})$ & -0.000123 & 0.24 & 0.3 \\
\hline $\mathrm{T}(n g / m l)$ & +0.0806 & 0.02 & 7.2 \\
\hline $\mathrm{BGP}(n g / m l)$ & -0.00236 & 0.0003 & 17.9 \\
\hline Total variance & & & 25.4 \\
\hline
\end{tabular}

* Original model also included T, height, caffeine, smoking, and calcium (NS).

‡ Original model also included height, caffeine, smoking, and calcium (NS).

spective study presented here demonstrate a role for the estrogens in rates of bone loss not only in the entire study population (with its wide range of estrogen concentrations), but also when restricted to those postmenopausal women with lower estrogen concentrations, and when all premenopausal visits are omitted. However, when the range of estrogen concentrations is restricted, as when perimenopausal visits are excluded, the estrogen-bone loss relationship is not as strong. Measures of estrogen dynamics, including $\mathrm{P}_{\mathrm{B}}$ and $\mathrm{MCR}$, were not better predictors of changes in bone mass than mean estrogen concentration. These other measurements were, however, made less frequently and were therefore more variable. Similarly, rates of change of E1 and E2 did not better predict rates of change in bone. Estrogen concentrations were, however, weaker predictors in general linear models where the range of estrogen concentrations was reduced, or where BGP concentrations were included. These findings confirm and extend previous findings that have suggested a critical role for estrogens in bone loss after oophorectomy $(2,3)$, as well as some case-control studies that have shown subjects with clinical osteoporosis to have lower concentrations of estrogens than comparison groups. Gotfredsen et al. have shown bone loss to be a generalized phenomenon, and estrogen prophylaxis to be effective at all sites (radius, spine, and femur) (15). Moreover, they have shown the radius sites to have the largest ratios of bone loss to precision of the measurement. Thus, they have suggested the use of the radius, as was done here, in studies of bone loss. It must be added, however, that conclusions regarding endogenous estrogens and the spine or hip will require studies specific to those sites, particularly since the estrogen effect was weaker at the distal (more trabecular) radius.
Equally important, these results clearly demonstrate that estrogen concentrations among those relatively estrogen-deficient subjects are associated with the rate of bone loss. When the early perimenopausal group was excluded, mean estrogen concentration remained a univariate predictor of rates of change in bone mass at the midshaft radius. When only postmenopausal visits were considered, a significant association between distal bone loss and estrogen remained, although the correlation between estrogen and midshaft bone loss was no longer significant. The results for the postmenopausal only group must be viewed cautiously, however, since the estimates of bone loss for those women who went through menopause during the study were much more variable (due to fewer observations for the calculation of slopes of bone mass), as evidenced by standard deviations $\sim 70 \%$ greater than for the same group using the entire 3-yr worth of measurements.

These data suggest that estrogen replacement therapy might better be given to those with lower endogenous estrogen concentrations. Since endometrial cancer risk may be greater among those with higher estrogen concentrations, treatment of only those with lower estrogen concentrations might provide the greatest benefit (reducing bone loss in those with the most rapid loss) with the least risk (treating only those at the lowest risk of endometrial cancer). Despite considerable controversy, similar arguments could be made with regard to enhancing the possible cardiovascular benefits of estrogen therapy.

Note that we used total estrogen concentrations in our analyses, and these levels would include the free, albuminbound and sex hormone-binding globulin-bound estrogen. Which of these is the biologically active form may vary according to the tissue considered (31). It is possible, at least for E2, that tighter correlations might have been found had we used the free and/or albumin-bound concentrations of estrogens in our analyses. However, the blood $P_{B}$ of the estrogens and androgens that are thought to reflect the biologically active moiety (32) had correlations not dissimilar from the total estrogens. Therefore, it is probable that measurements of the bound and free fractions would not have changed the results measurably.

The value of plasma estrogen concentration as a criterion for the selection of subjects for replacement therapy will depend on the answer to at least two questions. First, how well does a single measurement of an estrogen reflect the true status of a subject? In this study the median range for E1 (3-11 measurements per subject) was $36 \mathrm{pg} / \mathrm{ml}$, which included the irregularly cycling early perimenopausal women. Among postmenopausal women, the range was $\sim 26 \mathrm{pg} / \mathrm{ml}$. Thus, whereas the median range is not large, a single measurement would not accurately classify some individuals, despite the predictive value of a single estrogen measurement in a population. A second question, and an equally important one, is whether the response to exogenous estrogen can be predicted from the circulating estrogen concentrations. An answer to this would require a prospective study. Thus, although prospective assessment of plasma estrogens has clearly shown importance, among relatively estrogen-deficient subjects, the value of this measurement as a screening tool for determining which patients should receive estrogen replacement therapy will require further study.

This study also examined a potential mechanism for the effects of estrogen on bone. Several such mechanisms have been proposed, including effects on rates of bone remodelling 
$(17,19,20,33-35)$. Increased bone remodelling has been shown by calcium kinetics studies (17) to accompany estrogen deficiency. BGP has also been shown to be elevated during estrogen deficiency while administration of estrogen returns serum BGP to lower concentrations (19). In the current study, higher BGP concentrations were associated with more rapid bone loss and with lower estrogen concentrations. In multivariate models that did not include BGP, estrogen was the strongest predictor of rates of change in bone mass. When BGP was added (Tables VII and VIII), the statistical significance of the effect of estrogen was reduced to marginal or nonsignificance. This suggests that estrogen concentrations are important determinants (risk factors) of the rate of bone remodelling around the time of menopause, and that increased remodelling (BGP as a marker) due to a relative deficiency of estrogen leads to increased bone loss. However, the estrogen effect was not completely removed by the addition of BGP to the multivariable models, and, therefore, other mechanisms for the effect of estrogen may also be important, such as an effect on calcium absorption and vitamin D metabolism (34) or calcitonin secretion $(36,37)$. Estrogens have also been postulated to affect plasma phosphate (38), sensitivity of bone to parathyroid hormone (39), and other factors. Finally, the intraperson variability in the measurement of BGP would also reduce its ability to eliminate estrogen effects from the general linear models. It is also possible that BGP, as a marker of bone remodelling, is only coincidentally associated with estrogen action, although this seems unlikely.

$T$ concentrations were in all cases associated with distal rates of change in bone mass. The role of androgens in bone loss will require further study, particularly in other age groups where the effects of estrogens may be reduced.

Potentially important confounding factors influencing bone were also examined. Dietary calcium, was not significantly associated with midshaft loss in both analysis of variance and general linear models. Similarly, although caffeine intake has been reported to have a negative effect on calcium balance (40), it was not significant in the linear models. Thus, no conclusive evidence was seen to support strong calcium or caffeine effects, although the possibility of such effects cannot be ruled out by this study, since the design lacked adequate statistical power to examine nutritional effects.

Cigarette smoking, other hormones, obesity, and stature also did not achieve statistical significance in this study designed to examine estrogen effects.

Although the dependent variable in this study was bone mass (grams per centimeter), adjustment of these values to bone "density" (grams/centimeter per centimeter) by dividing by bone width did not significantly alter any of these results.

Endogenous estrogen concentrations, perhaps through effects on remodelling, appear to be an important factor in bone loss around the time of menopause. Although mean BGP concentration was a "stronger" predictor of bone loss than estrogen concentrations, the most likely biological mechanism would be that declines in estrogen concentration cause increased bone remodelling, thereby yielding increased serum concentrations of BGP. No data suggested an estrogen (or BGP) threshold effect, nor did bone loss accelerate immediately after cessation of menses. Whereas it remains possible that some event coincident with declines in estrogen production may be responsible for the effects noted, other data supported a primary role for estrogen. For example, even among women with relatively low estrogen concentrations, a relationship between bone loss and estrogen was present. Therapy to prevent osteoporosis has thus far been implemented on uncertain criteria. The results of this study offer some promise in this regard, since those subjects with high BGP and low estrogen concentrations have high rates of bone loss, and might be the best candidates for estrogen replacement therapy.

\section{Acknowledgments}

This research was supported by U. S. Public Health Service, National Institutes of Health grants AG 02927 and P01-AG05793.

\section{References}

1. Riggs, B. L., and L. J. Melton. 1986. Involutional osteoporosis. N. Engl. J. Med. 314:1676-1686.

2. Horsman, A., M. Simpson, P. A. Kirby, and B. E. C. Nordin. 1977. Non-linear bone loss in oophorectomized women. Br. J. Radiol. 50:504-507.

3. Genant, H. K., C. E. Cann, B. Ettinger, and G. S. Gordan. 1982. Quantitative computed tomography of vertebral spongiosa: a sensitive method for detecting early bone loss after oophorectomy. Ann. Intern. Med. 97:699-705.

4. Abdallh, H., D. M. Hart, and R. Lindsay. 1984. Differential bone loss and effects of long-term estrogen therapy according to time of introduction of therapy after oophorectomy. In Osetoporosis. C. Christiansen, C. D. Arnaud, B. E. C. Nordin, A. M. Parfitt, W. A. Peck, and B. L. Riggs, editors. Department of Clinical Chemistry Glostrup Hospital, Glostrup. 621-623.

5. Lindsay, R., D. M. Hart, C. Forrest, and C. Baird. 1980. Prevention of spinal osteoporosis in oophorectomized women. Lancet. 2:1151-1153.

6. Christiansen, C., M. S. Christensen, P. McNair, C. Hagen, K-Estocklund, and I. Transbol. 1980. Prevention of early postmenopausal bone loss: controlled 2-year study in $\mathbf{3 1 5}$ normal females. Eur. J. Clin. Invest. 10:273-279.

7. Ettinger, B., H. K. Genant, and C. Cann. 1985. Long-term estrogen therapy prevents fractures and preserves bone mass. Ann. Intern. Med. 102:319-324.

8. Marshall, D. H., R. C. Crilly, and B. E. C. Nordin. 1977. Plasma androstenedione and oestrone levels in normal and osteoporotic postmenopausal women. Br. Med. J. 2:1177-1179.

9. Longcope, C., R. S. Baker, S. L. Hui, and C. C. Johnston, Jr. 1984. Androgen and estrogen dynamics in women with vertebral crush fractures. Maturitas. 6:309-318.

10. Davidson, B. J., B. L. Riggs, H. W. Wahner, and H. L. Judd. 1983. Endogenous cortisol and sex steroids in patients with osteoporotic spinal fractures. Obstet. Gynecol. 61:275-278.

11. Riggs, B. L., R. J. Ryan, H. W. Wahner, N. S. Jiang, and V. R. Mattox. 1973. Serum concentations of estrogen, testosterone and gonadotropins in osteoporotic and non-osteoporotic postmenopausal women. J. Clin. Endocrinol. \& Metab. 36:1097-1099.

12. Dequeker, J. and P. Geusens. 1985. Contributions of aging and estrogen deficiency to postmenopausal bone loss. N. Engl. J. Med. 313:453.

13. Riggs, B. L., H. W. Wahner, W. L. Dunn, R. B. Mazess, K. P. Offord, and L. J. Melton, III. 1981. Differential changes in bone mineral density of the appendicular and axial skeleton with aging. J. Clin. Invest. 67:328-335.

14. Riggs, B. L., H. W. Wahner, L. J. Melton, III, L. S. Richelson, H. L. Judd, and K. P. Offord. 1986. Rates of bone loss in the appendicular and axial skeletons of women. J. Clin. Invest. 77:1487-1491.

15. Gotfredsen, A., L. Nilal, B. J. Riis, K. Thomsen, and C. Christiansen. 1986. Bone changes occuring spontaneously and caused by 
oestrogen in early postmenopausal women: a local or generalised phenomenon? Br. Med. J. 292:1098-1100.

16. Riis, B. J., C. Christiansen, L. J. Deftos, and B. D. Catherwood. 1984. The role of serum concentrations of estrogens in postmenopausal osteoporosis and bone turnover. In Osteoporosis. C. Christiansen, C. D. Arnaud, B. E. C. Nordin, A. M. Parfitt, W. A. Peck, and B. L. Riggs, editors. Department of Clinical Chemistry Glostrup Hospital, Glostrup. 333-336.

17. Heaney, R. P., R. R. Recker, and P. D. Saville. 1978. Menopausal changes in bone remodeling. J. Lab. Clin. Med. 92:964-970.

18. Gallagher, J. C., M. N. Young, and B. E. C. Nordin. 1972. Effects of artificial menopause on plasma and urine calcium and phosphate. Clin. Endocrinol. 1:57-64.

19. Delmas, P. D., D. Stenner, H. W. Wahner, K. G. Mann, and B. L. Riggs. 1983. Increase in serum bone-carboxyglutamic acid protein with aging in women. J. Clin. Invest. 71:1316-1321.

20. Fogelman, I., J. W. Poser, M. L. Smith, D. M. Hart, and J. A. Bevan. 1984. Alterations in skeletal metabolism following oophorectomy. In Osteoporosis. C. Christiansen, C. D. Arnaud, B. E. C. Nordin, A. M. Parfitt, W. A. Peck, and B. L. Riggs, editors. Department of Clinical Chemistry Glostrup Hospital, Glostrup. 519-521.

21. Cameron, J. R., R. B. Mazess, and J. A. Sorenson. 1968. Precision and accuracy of bone mineral determination by direct photon absorptiometry. Invest. Radiol. 3:141-150.

22. Schlenker, R. A., and W. W. VonSeggen. 1976. The distribution of cortical and trabecular bone mass along the lengths of the radius and ulna and the implications for in vivo bone mass measurements. Calcif. Tissue Res. 20:41-52.

23. Longcope, C., D. Watson, and K. I. H. Williams. 1974. The effects of synthetic estrogens on the metabolic clearance and production rates of estrone and estradiol. Steroids. 24:15-30.

24. Pratt, J. H., and C. Longcope. 1978. Effect of adrenocorticotropin on production rates and metabolic clearance rates of testosterone and estradiol. J. Clin. Endocrinol. \& Metab. 47:307-313.

25. Baird, D. T., R. Horton, C. Longcope, and J. F. Tait. 1969. Steroid dynamics under steady state conditions. Recent. Prog. Horm. Res. 25:611-644.

26. Longcope, C. 1982. Methods and results of aromatization studies in vivo. Cancer Res. 42:3307S-3311S.

27. Longcope, C., T. Kato, and R. Horton. 1969. Conversion of blood androgens to estrogens in normal adult men and women. J. Clin. Invest. 48:2191-2201.
28. Longcope, C., J. H. Pratt, S. H. Schneider, and S. E. Fineberg. 1978. Aromatization of androgens by muscle and adipose tissue in vivo. J. Clin. Endocrinol. \& Metab. 46:146-152.

29. Epstein, S., J. Poser, R. McClintock, C. C. Johnston, Jr., G. Bryce, and S. Hui. 1984. Differences in serum bone gla protein with age and sex. Lancet. 1:307-310.

30. Hui, S. L., and J. O. Berger. 1983. Empirical Bayes estimation of rates in longitudinal studies. J. Am. Stat. Assoc. 78:753-760.

31. Verheugen, C., W. M. Pardridge, H. L. Judd, and G. Chaudhuri. 1984. Differential permeability of uterine and liver vascular beds to estrogens and estrogen conjugates. J. Clin. Endocrinol. \& Metab. 59:1128-1132.

32. Baird, D., R. Horton, C. Longcope, and J. F. Tait. 1969. Steroid prehormones. Perspect. Biol. Med. 11:384-421.

33. Aitken, J. M., D. M. Hart, and D. A. Smith. 1971. The effect of long-term mestranol administration on calcium and phosphorus homeostasis in oophorectomized women. Clin. Sci. (Lond.). 41:233-236.

34. Gallagher, J. C., B. L. Riggs, and H. F. DeLuca. 1980. Effect of estrogen on calcium absorption and serum vitamin $\mathrm{D}$ metabolites in postmenopausal osteoporosis. J. Clin. Endocrinol. \& Metab. 51:13591364.

35. Gallagher, J. C., and B. E. C. Nordin. 1973. Oestrogen and calcium metabolism. In Aging and Estrogens. Frontiers of Hormone Research. Vol. 2. P. A. VanKeep and C. LaRitven, editors. S. Karger AG, Basel, Switzerland. 2:98-117.

36. Deftos, L. J., M. H. Weisman, G. W. Williams, D. B. Karpf, A. M. Frumar, B. J. Davidson, J. G. Parthemore, and H. L. Judd. 1980. Influence of age and sex on plasma calcitonin in human beings. N. Engl. J. Med. 302:1351.

37. Stevenson, J. C., C. J. Hillyard, G. Abeyasekera, K. G. Phang, and I. MacIntyre. 1981. Calcitonin and the calcium-regulating hormones in postmenopausal women: effect of oestrogens. Lancet 1:693695.

38. Selby, P. L., M. Peacock, S. A. Barkworth, W. B. Brown, and G. A. Taylor. 1985. Early effects of ethinyloestradiol and norethisterone treatment in post-menopausal women on bone resorption and calcium regulating hormones. 1985. Clin. Sci. (Lond.). 69:265-271.

39. Heaney, R. P. 1965. A unified concept of osteoporosis. Am. J. Med. 39:877.

40. Heaney, R. P., and R. R. Recker. 1982. Effects of nitrogen, phosphorus, and caffeine on calcium balance in women. J. Lab. Clin. Med. 99:46-55. 